\title{
Study OF The Transient Processes IMPaCt ON THE DieSEl Fuel CONSUMPTION WHILE IN SERVICE
}

\author{
Sergey Ovcharenko, Vitaliy Chetvergov
}
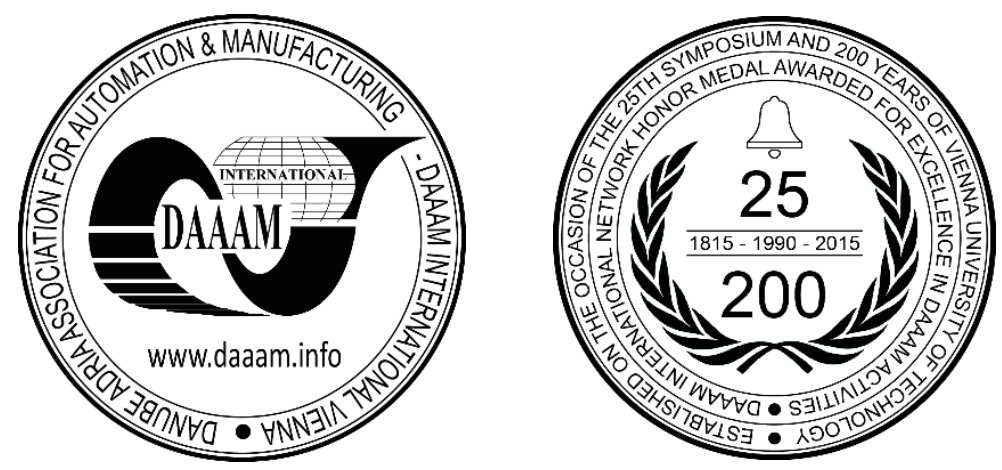

This Publication has to be referred as: Ovcharenko, S[ergey] \& Chetvergov, V[italiy] (2016). Study of the Transient Processes Impact on the Diesel Fuel Consumption While in Service, Proceedings of the 27th DAAAM International Symposium, pp.0886-0891, B. Katalinic (Ed.), Published by DAAAM International, ISBN 978-3-902734-08-2, ISSN 1726-9679, Vienna, Austria

DOI: $10.2507 / 27$ th.daaam.proceedings. 127

\begin{abstract}
This paper shows the study results of transient processes parameters of the diesel locomotive engine of the shunting locomotive. The paper discusses the transient processes impact on the diesel fuel consumption using results of experimental runs. The result is a theoretical model for calculating the coefficient of the transient processes impact on the fuel consumption.
\end{abstract}

Keywords: diesel; fuel consumption; transient process; locomotive; fuel consumption rate.

\section{Introduction}

Providing traffic by railway transport associated with need to perform an auxiliary shunting operations, that has a number of features complicating the formation of fuel consumption rates per trip. The complexity of consideration of this factor leads to an increase of the diesel fuel consumption and traffic costs.

Exploitation of shunting locomotives associated with frequent changes of diesel-generator set (DGS) operating mode. According to the author [1] the overall duration of the diesel shunting locomotive in a transient mode can reach $20-40 \%$ of the total operating time.

Solution to the problem of formation of the science-based standards of the fuel consumption rate per trip for shunting work is possible through the use of a mathematical model that takes into account the impact of transient processes on the increase in fuel consumption. Scientific papers of authors [2, 3, 4] and several other are dedicated to research of work process parameters when changing the operation mode of diesel. The main problem which is solved in these studies is the optimization of operating influences of the fuel equipment management system in order to improve economic and ecological characteristics of diesel.

The dependence of the increase in fuel consumption in the transition process as compared with the established operation mode of diesel was set as a result of experimental studies. Duration of the transition process was set when passing of the diesel operation mode from one to another control notch. Influence coefficient of transient processes number on the diesel fuel consumption during operation was proposed in the paper. Correlation dependence of the influence coefficient of transient processes number on the diesel fuel consumption on the number of transient processes per trip was obtained. 


\section{Analysis of experiments}

The analysis of the experimental data obtained by several motive-power depot of industrial railway transport allows to state that within 10-12 operating hours of a shunting locomotive the switching number $\mathrm{n}$ of control notches (of transient processes) can reach 2500 . Figure 1 shows the results of the studies presented in the form of distribution of the switching number $n$ of control notches per trip.

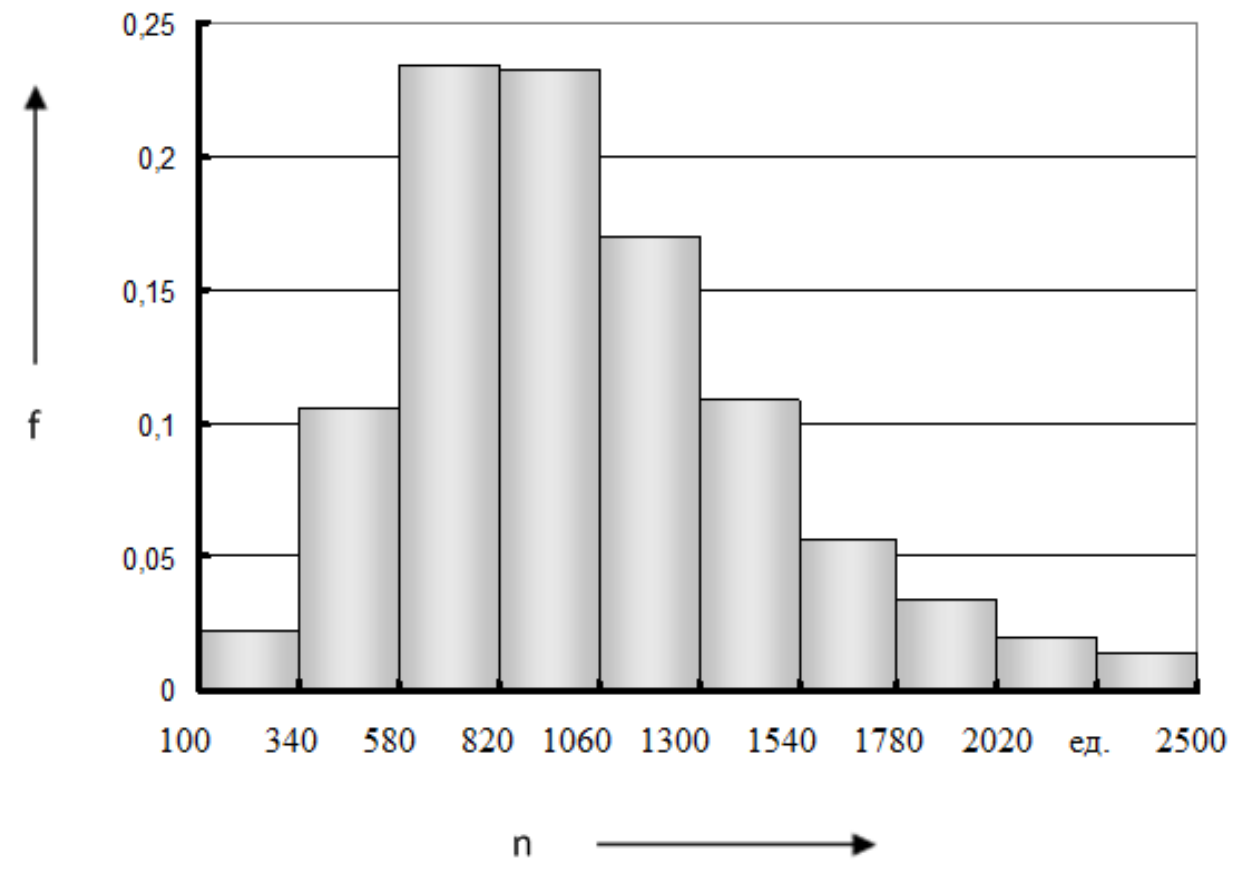

Fig. 1. The distribution of the switching number $n$ of control notches per shift

When changing the controller handle from one position to another the speed governor of crankshaft and capacity controls the fuel supply by moving the fuel injection pump racks. The rack rotates a fuel pump plunger, thereby changing the positioning of edge 1 (Fig. 2) relative to the opening 2 through which the fuel fills a space above the plunger. The plunger explosion stroke increases (decreases) and a certain amount of diesel fuel supplied into the combustion chamber. Figure 3 presents the dependence of the cyclic fuel delivery $(b, g)$ on the rack output of fuel pump $(h, m m)$ for diesel PD1M (ПД1M - in original).

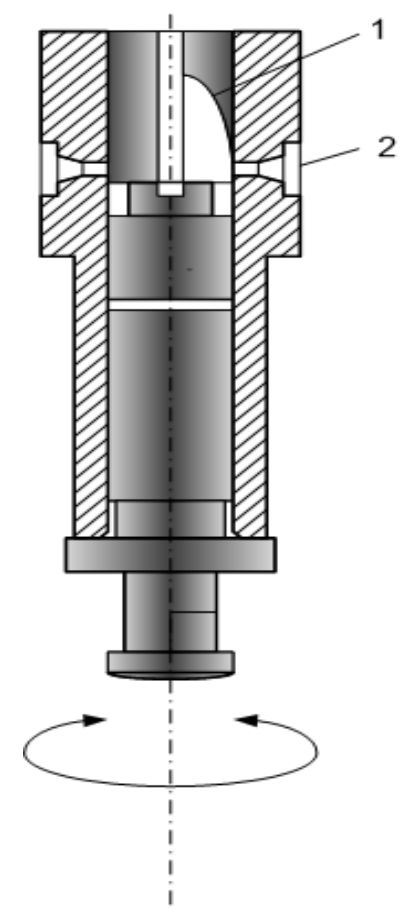

Fig. 2. Fuel injection pump plunger 


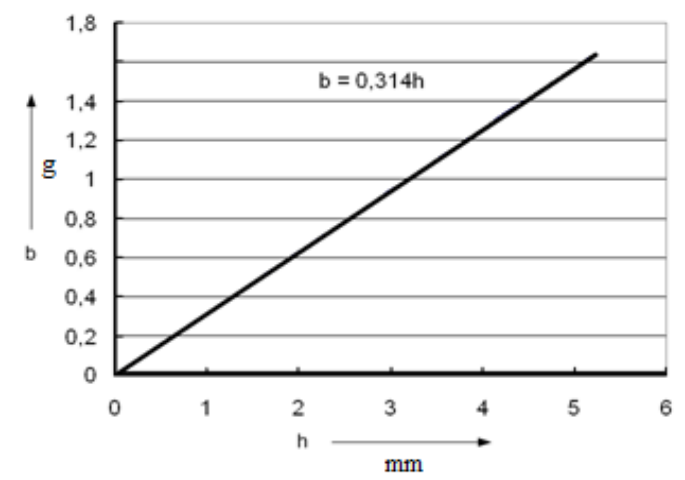

Fig. 3. The dependence of the cyclic fuel delivery on the effective stroke of fuel injection pump plunger

The frequency stabilization process of engine crankshaft rotation corresponding to the installed operation mode of diesel-generator set occurs for a while when the fuel consumption is increased. The equation for an approximate evaluation of the difference between the cycle fuel supply in the transient and steady operation mode of diesel-generator set is provided in [5]:

$$
\Delta q_{\tilde{\mathrm{o}}}=J_{\Sigma} \frac{d P_{\tilde{\mathrm{A}}}}{d t}\left(\frac{\partial M_{\tilde{\mathrm{A}}}}{\partial \omega_{\ddot{\mathrm{A}}}} \omega_{\ddot{\AA}}+M_{\tilde{\AA}}\right)^{-1} H_{u}^{-1} \eta_{e}^{-1} \omega_{\tilde{\AA}}^{-1} z \pi \tau
$$

where $J_{\Sigma}$ is a moment of inertia of the rotating diesel-generator masses and auxiliary equipment of locomotive with diesel drive;

$P_{\tilde{\AA}}$ is a traction generator capacity;

$t$ is a time;

$M_{\tilde{\AA}}$ is a moment, being passed to generator shaft;

$\omega_{\ddot{\mathrm{A}}}$ is aT angular velocity of diesel crankshaft;

$H_{u}$ is a fuel calorific efficiency;

$\eta_{e}$ is an effective efficiency of diesel in steady mode;

$z$ is a number of diesel cylinders;

$\tau$ is a cycle coefficient of diesel.

Taking into account that the work process parameters change in transient mode, the use of equation (1) for calculating the influence coefficient of transition process on the diesel fuel consumption is difficult in practical calculations.

To evaluate the impact degree of a number of main controller switching on increasing the fuel consumption the experimental studies were conducted on shunting locomotives at carrying out of the rheostat tests. The inductive displacement sensor was mounted on the fuel pump rack. It allows to fix the rack output with $1 \mathrm{~mm}$ resolution and maximum displacement of $60 \mathrm{~mm}$, provided that the maximum possible rack output of rails is $40 \mathrm{~mm}$. The rack displacement was recorded through $0.1 \mathrm{~s}$. Figures 4 and 5 presents the temporary implementation of fuel pump rack during transient processes of the diesel PD1M of the locomotive series TEM2 obtained from the results of the experiment in load conditions and idle running. The control notches set was carried out from minimum to maximum and back again with time delay in order to stabilize the fuel supply at every transient process.

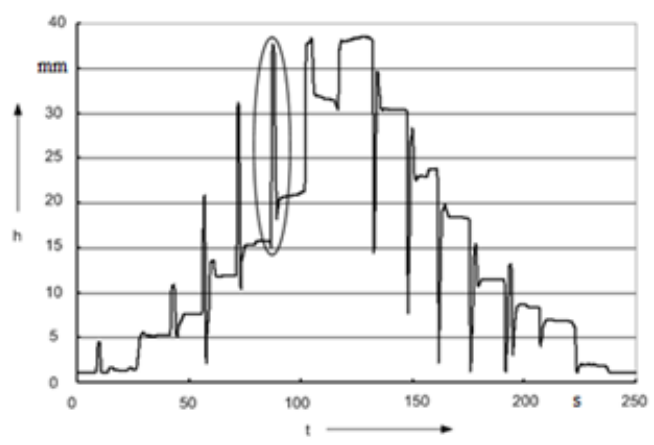

Fig. 4. Output of fuel injection pump racks during transient processes in load conditions 


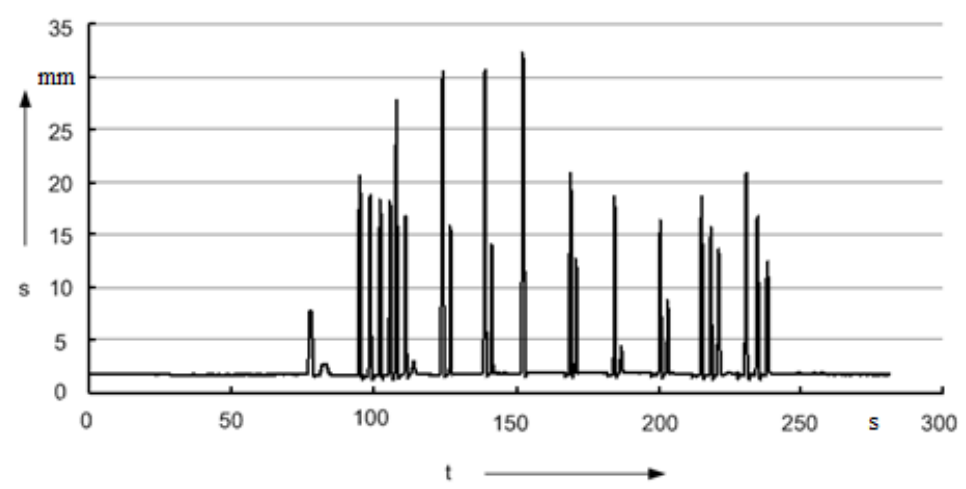

Fig. 5. Output of fuel injection pump racks during transient processes in idle running

The fuel pump rack output is proportional to the cyclic fuel supply. To evaluate the degree of transient processes influence over the diesel fuel consumption is enough to compare the area bounded by line 1 (Figure 6) in the transient process and the rectangle 2 , characterizing the fuel consumption in the steady process.

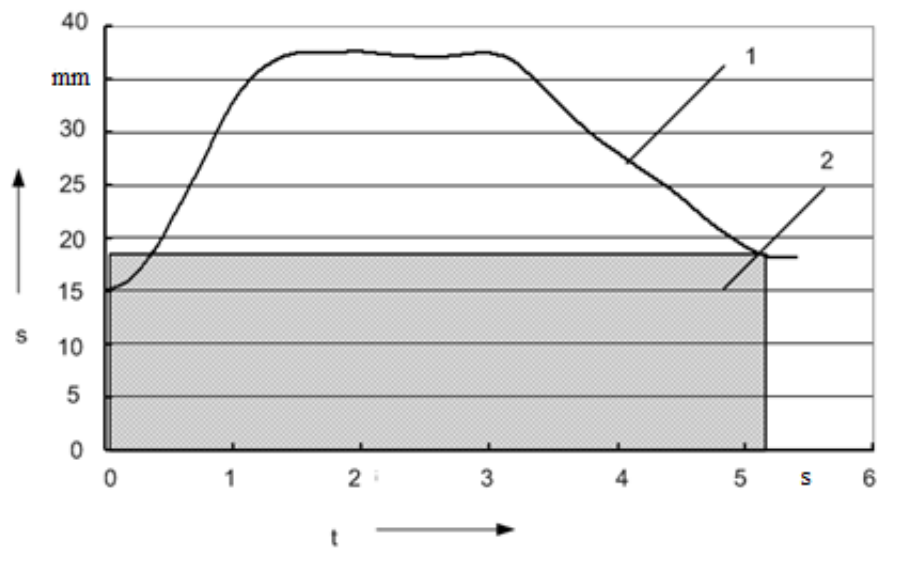

Fig. 6. Fragment of the transient process

As a result of the experimental data processing we found that the duration of the transient process for diesel PD1M is an average of 5 seconds. To calculate the area bounded by a line 1 (Fig. 6), the fuel pump rack output in the transient process was described by $5^{\text {th }}$ degree Lagrange polynomial:

$$
H(t)=\sum_{i=0}^{5} h_{i} \prod_{\substack{j=0 \\ j \neq i}}^{5} \frac{t-t_{j}}{t_{i}-t_{j}}
$$

The area obtained by polynomial integrating in the time interval $0-5 \mathrm{~s}$ :

$$
S=\int_{0}^{5} H(t) d t
$$

According to analysis of the experiment results the mathematical expectation of exceeding the fuel consumption during the transient processes relative to the steady state is accepted as $43 \%$ in load conditions and $25 \%$ in idle running.

In practical calculations the transient processes impact on the fuel consumption is taken into account by coefficient $K_{\tilde{I}}$. Theoretical value of $K_{\tilde{I}}$ can be obtained based on the assumption of equality calculated diesel fuel consumption in all operation modes of the diesel-generator set and fuel consumption subject to the experimentally established impact degree of the transient processes in load conditions and idle running.

$$
\left(\sum_{i=0}^{8} b_{x i} t_{x i}+\sum_{i=1}^{8} b_{n i} N_{i} t_{n i}\right) K_{\mathrm{I}}=\left(\sum_{i=0}^{8} b_{x i} t_{x i}+\sum_{i=1}^{8} b_{n i} N_{i} t_{n i}\right)+\sum_{i=0}^{8} b_{x i}\left(d_{x}-1\right) n t_{\text {İ }} K_{x}+\sum_{i=1}^{8} b_{n i}\left(d_{n}-1\right) n t_{\text {I }} K_{n}
$$


where $i$ is a number of control notches;

$b_{x i}$ is a fuel consumption on control notches in idle running, $\mathrm{kg} / \mathrm{h}$;

$b_{n i}$ is a fuel consumption on control notches in load conditions, $\mathrm{kg} / \mathrm{kW} \cdot \mathrm{h}$;

$t_{x i}, t_{n i}$ are a work time of locomotive diesel-generator set on control notches in idle running and under load conditions respectively, h;

$t_{\tilde{\mathrm{I}}}=0,0013$ is a set time of the transient process, $\mathrm{h}$;

$d_{x}, d_{n}$ are a transient processes share attributable to the idle running and load conditions respectively;

$K_{x}, K_{n}$ are an impact coefficients of transient processes on increasing the fuel consumption in idle running and load conditions respectively;

$N_{i}$ is a locomotive diesel-generator set capacity on control notches, $\mathrm{kW}$;

$n$ is a number of transient processes.

From the equation (4):

$$
K_{\Pi}=1+\frac{\sum_{i=0}^{8} b_{x i}\left(d_{x}-1\right) n t_{\Pi} K_{x}+\sum_{i=1}^{8} b_{n i}\left(d_{n}-1\right) n t_{\Pi} K_{n}}{\sum_{i=0}^{8} b_{x i} t_{x i}+\sum_{i=1}^{8} b_{n i} N_{i} t_{n i}}
$$

Figure 7 provides the results of numerical simulation of $K_{\Pi}$ when changing the number of transient processes from 0 to 2500 and the ratio of the transient processes share in load conditions and idle running $d_{n}, d_{x}\left(d_{n}+d_{x}=1\right)$.

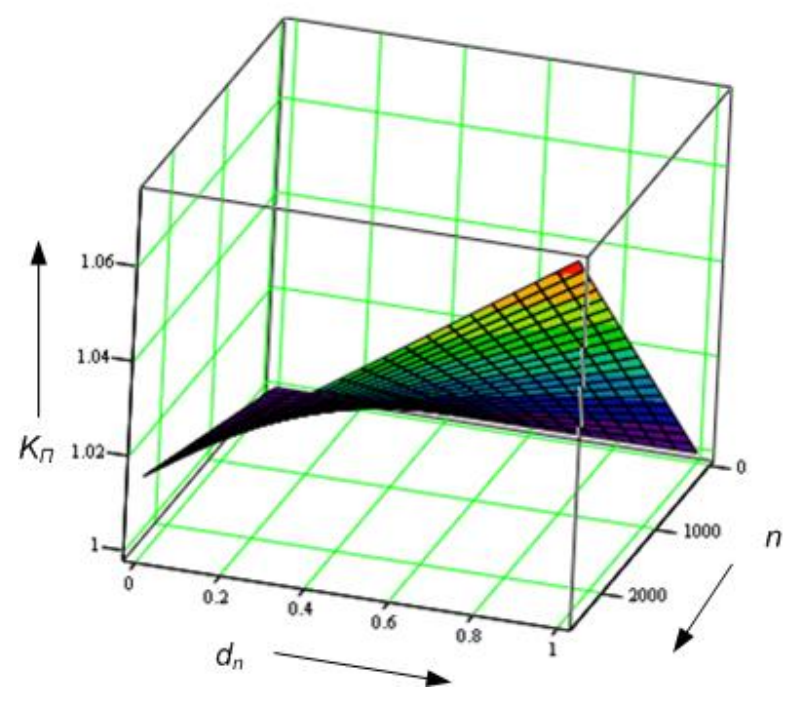

Fig. 7. The surface of the coefficient $K_{I I}$ values on the number of transient processes and their redistribution on operating modes of diesel-generator set

Random factors influence the fuel consumption during the operation of locomotives. To take into account these factors is very problematic in the theoretical simulation. Experimental trip in which operation modes of locomotive dieselgenerator set were recorded, a number of transient processes and actual fuel consumption were conducted to evaluate the impact of transient processes on increasing the fuel consumption. Fuel quantity consumed by diesel-generator set was assessed during the obtaining of the dependence $K_{\Pi}^{\prime}=f(n)$ from an actual fuel consumption using combustion characteristic. Remaining fuel share refers to the increase due to transient processes. The impact of number of dieselgenerator set transient processes on fuel consumption was found as a result of experimental trips (Fig. 8). Average number of control notches switching in a minute by the trip results is indicated on the abscissa. Constituent value of the coefficient of fuel consumption increasing is located on the ordinate. Analysis of regression dependence allows to assert that the impact degree of transient processes established by experimental trip results on the fuel consumption agrees with the results of theoretical research and can reach 6-8\%. 


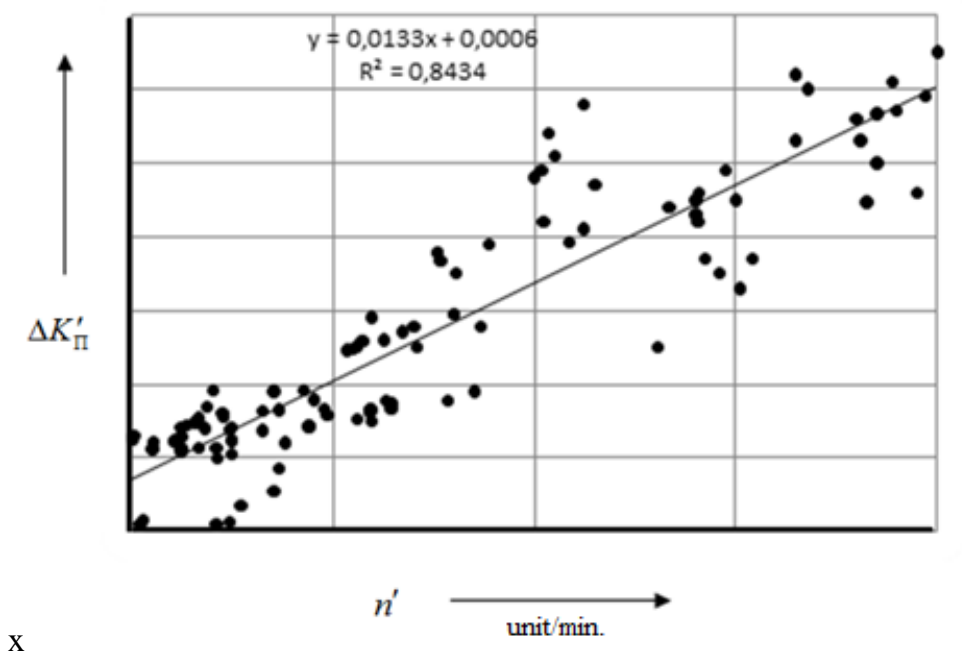

Fig. 8. Influence of transient processes on fuel consumption coefficient by experimental trip results

\section{Conclusion}

1) When diesel operates on transient process, a fuel consumption is increased by $43 \%$ in load conditions and $25 \%$ in idle running;

2) The results of theoretical calculations allow us to conclude that by increasing the operating time of diesel-generator set in the transient processes, the increase in fuel consumption per shift can reach 6-8\%;

3) Equation for calculating $K_{\Pi}$ was obtained for practical calculations. The equation allows taking into account the impact of transients processes on locomotive fuel consumption;

4) The results allow to move to the implementation of a science-based fuel consumption rate per trip using the onboard electronic systems for controlling the work parameters of locomotive diesel on shunting operations.

\section{References}

[1] Homich, A.; Tupitsyn, O.; Simson, A. (1975). Fuel Economy and Thermotechnical Modernization of Locomotives, Transport

[2] Kurapin, A.; Slavutskiy, V. (2014). Research of transient processes in fuel-injection equipment of autotractor diesel by experimental frequency method. Proceedings of the Volgograd Technical University, Vol. 145, No. 18, pp. 2126

[3] Markov, V.; Polukhin, E. (2008). Diesel transient processes with angle control system of fuel injection timing advance. Proceedings of the Universities. Mechanical Engineering, No. 5, pp. 33-65

[4] Gorelik, G. (2008). Study of the relationship between fuel supply and mixture formation with the working process in diesels operating on sharing modes. Journal of Pacific State University, Vol. 8, No. 1, pp. 75-90

[5] Kosov, E.; Sukhoparov, S. (1999). Operating Modes Optimization of the Locomotive Diesel Generators, Intext 